\title{
PERAN REFRAKSIONIS OPTISIEN PADA PEMERIKSAAN MATA DI BIDANG HUKUM DALAM UPAYA PENINGKATAN PELAYANAN KESEHATAN MATA MASYARAKAT
}

\author{
Mochammad Kholil \\ STIKES Widya Husada Semarang \\ m.kholil.cr7@gmail.com
}

\begin{abstract}
Optical Refraction Service is Optical / Optometric Refractionion is an integral part of health service, an important condition with increasing prevalence of refractive and eye disease, but still occurs Refraction Optisien does not implement standard of refractive optic service. The purpose of this study was to analyze the protection of optical patient's law in eye health service and the factors which become the reason of patient's dissatisfaction toward optical refractionion in eye health service in Semarang city. Research method is juridical normative empirical and the research specification used is descriptive analytical. Data used in this research is secondary data and primary data. Secondary data includes primary, secondary and tertiary legal materials, while primary data is obtained through field research (field Research). The result of the Research, it can be concluded that the illegal act done by Refractionist Optisien for not doing standard of refraction service due to lack of supervision and lack of knowledge about SOP about the legislation. The legal consequences for Optisien Refractionation that do not protect the optical patient are never implemented due to lack of supervision and guidance from Dinas Kesehatan. socialization to Optisien Refraksionis with the holding of seminars and workshops, and need sanction firmly against Refraction Optisien who do work not according to SOP
\end{abstract}

Key words : $\quad$ Patient Protection Law, Refraksionis optical dispensers, Eye Health Care

\begin{abstract}
ABSTRAK
Pelayanan Refraksi optisi adalah Refraksionis Optisien / Optometris merupakan bagian integral pelayanan kesehatan, menjadi syarat penting dengan meningkatnya prevalensi kelainan refraksi dan penyakit mata, namun masih terjadi Refraksionis Optisien tidak melaksanakan standard pelayanan refraksionis optisien. Tujuan penelitian untuk menganalisis perlindungan hukum pasien optikal dalam pelayanan kesehatan mata dan faktor-faktor yang menjadi alasan ketidakpuasan pasien terhadap refraksionis optisien dalam pelayanan kesehatan mata di kota Semarang.

Metode penelitian ini adalah yuridis normatif empiris dan spesifikasi penelitian yang digunakan adalah deskriptif analitis. Data yang digunakan dalam penelitian ini adalah data sekunder dan data primer. Data sekunder meliputi bahan hukum primer, sekunder dan tersier, sedangkan data primer diperoleh melalui penelitian lapangan (field Research). Hasil penelitian, bahwa perbuatan melawan hukum yang dilakukan oleh Refraksionis Optisien karena tidak melakukan standar pelayanan refraksi dikarenakan kurangnya pengawasan dan kurangnya pengetahuan tentang SOP tentang peraturan perundang undangan, Akibat hukum bagi Refraksionis Optisien yang tidak melindungi pasien optikal tidak pernah dilaksanakan karena kurangnya pengawasan dan pembinaan dari Dinas Kesehatan. Rekomendasi perlu diadakan sosialisasi terhadap Refraksionis Optisien dengan diadakannya seminar dan workshop, dan perlu sanksi tegas terhadap Refraksionis Optisien yang melakukan pekerjaannya tidak sesuai SOP.
\end{abstract}

Kata Kunci : Perlindungan Hukum Pasien, Refraksionis Optisien, Pelayanan Kesehatan Mata 


\section{PENDAHULUAN}

Pembangunan kesehatan sebagai bagian integral dari pembangunan nasional pada hakekatnya adalah penyelenggaraan upaya kesehatan untuk mencapai kemampuan hidup sehat bagi setiap penduduk agar dapat mewujudkan derajat kesehatan yang optimal. Untuk mewujudkan hal tersebut diperlukan upaya yang menyeluruh meliputi peningkatan mutu dan aksesibilitas terhadap tenaga, sarana, prasarana dan peralatan di fasilitas pelayanan kesehatan. Pelayanan refraksi optisi/optometri merupakan bagian integral dari pelayanan kesehatan dimana kebutuhan akan pelayanan refraksi optisi/optometri pada fasilitas pelayanan kesehatan akan cenderung meningkat sehubungan dengan meningkatnya prevalensi kelainan refraksi dan penyakit mata dan/atau kebutaan yang diakibatkannya. Guna memenuhi tuntutan pelayanan refraksi optisi/optometri di fasilitas pelayanan kesehatan diperlukan standar pelayanan sehingga pelayanan refraksi optisi/optometri disetiap fasilitas pelayanan kesehatan memiliki keseragaman, bermutu dan dapat dipertanggung jawabkan. Untuk dapat memenuhi kebutuhan masyarakat akan pelayanan kesehatan yang aman, bermutu dan terjangkau, pemerintah telah menggulirkan berbagai macam kebijakan. Salah satu kebijakan penting lainnya, pemerintah telah mengajak peran serta masyarakat dan pihak swasta untuk ikut ambil bagian dalam upaya pemenuhan sarana pelayanan kesehatan.
Upaya pemerintah tersebut telah membawa hasil yang menggembirakan, sehingga di era globalisasi ini dapat ditemukan berbagai macam sarana kesehatan di Indonesia yang dapat memberikan jasa pelayanan kesehatan kepada masyarat, termasuk didalamnya adalah pelayanan kesehatan mata.

Sejak tahun 2005, upaya pelayanan kesehatan mata telah diarahkan untuk dapat menanggulangi gangguan penglihatan dan mencegah terjadinya kebutaan di Indonesia. Berdasarkan hasil survei yang telah dilakukan Kementrian Kesehatan R.I. menunjukkan bahwa angka gangguan penglihatan dan kebutaan di Indonesia semakin meningkat, dari $1,2 \%$ (1982) menjadi 1,5\% (1993-1996). Ditinjau dari faktor penyebabnya, dari jumlah tersebut $0,78 \%$ disebabkan karena katarak, 0,20\% disebabkan karena glaucoma, 0,14\% disebabkan karena kelainan refraksi dan 0,38\% disebabkan oleh penyakit-penyakit lain yang berhubungan dengan usia lanjut. ${ }^{1}$ Data tersebut menunjukan, bahwa tingginya angka gangguan penglihatan dan kebutaan di Indonesia telah menjadi masalah sosial yang perlu ditanggulangi secara terkoordinasi dengan melibatkan berbagai sektor, baik dari sektor pemerintah maupun swasta.

Sesuai dengan kebutuhan pelayanan kesehatan mata yang diinginkannya, sekarang masyarakat dapat mengunjungi berbagai sarana pelayanan kesehatan seperti halnya Puskesmas, Klinik Mata, Rumah Sakit maupun Optikal. Bila pelayanan kesehatan mata 
JURNAL SEHAT MASADA VOLUME XIV NOMOR 1 Januari $2020 \quad$ ISSN : 1979-2344

yang diinginkannya itu berkaitan dengan kebutuhan lensa kontak dan/atau kacamata sebagai alat bantu penglihatan, maka sarana kesehatan yang paling tepat untuk dikunjungi adalah optikal. Dalam hal ini yang dimaksud dengan optikal adalah sarana kesehatan yang menyelenggarakan pelayanan pemeriksaan mata dasar, pemeriksaan refraksi serta pelayanan kacamata koreksi dan/atau lensa kontak. Untuk melindungi masyarakat dari pelayanan optikal yang dapat merugikan kesehatan, pemerintah melalui Kepmenkes RI Nomor 41 Tahun 2015 tentang standar pelayanan refraksionis optisien menetapkan suatu kebijakan, bahwa dalam standarisasi pelayanan refraksi optisi/optometri di fasilitas pelayanan kesehatan diperlukan untuk terwujudnya keseragaman dalam peningkatan mutu pelayanan refraksi optisi/optometri yang profesional, komprehensif, terpadu, merata dan terjangkau sehingga dapat memberikan kontribusi untuk terwujudnya derajat kesehatan masyarakat yang optimal berorientasi kepada kepuasan pasien/klien dan masyarakat. Oleh karena itu, penerapan standar pelayanan refraksi optisi/optometri pada fasilitas pelayanan kesehatan ini menjadi bagian penting dari upaya peningkatan mutu pelayanan kesehatan secara keseluruhan, dan akan dilakukan bimbingan, monitoring dan evaluasi secara berkala dan berkesinambungan. Dengan adanya ketentuan tersebut, maka seluruh kegiatan optikal yang berkaitan dengan pemeriksaan mata dasar, pemeriksaan refraksi serta pelayanan kacamata koreksi dan/atau lensa kontak menjadi tanggung jawab refraksionis optisien.

Dalam hal ini yang dimaksud dengan hukum kesehatan adalah himpunan dari berbagai produk hukum yang memuat ketentuan hukum, yang berhubungan langsung dengan pemeliharaan atau pelayanan kesehatan dan penerapannya, serta mengatur hubungan antara penerima dan pemberi jasa layanan kesehatan, termasuk hak dan kewajiban masing-masing. ${ }^{2}$ Menurut Van Der Mijn, Hukum kesehatan diartikan sebagai hukum yang berhubungan langsung dengan pemeliharaan kesehatan, meliputi penerapan perangkat hukum perdata, pidana dan tata usaha negara. ${ }^{3}$

Dengan demikian, bila seorang Refraksionis Optisien dalam menjalankan kegiatan profesinya tidak sesuai dengan hak dan kewajibannya sehingga mengakibatkan timbulnya kerugian atau cidera bagi konsumen kesehatan yang dilayaninya, maka yang bersangkutan harus bertanggung jawab secara hukum. Dalam hal ini tanggung jawab hukum diartikan sebagai sesuatu akibat lebih lanjut dari pelaksaan peranan, baik peranan itu merupakan hak dan kewajiban ataupun kekuasaan. Secara umum tanggung jawab hukum diartikan sebagai kewajiban untuk melakukan sesuatu atau berprilaku menurut cara tertentu tidak menyimpang dari pertaturan yang telah ada. $^{4}$ Sedangkan Purbacaraka berpendapat bahwa tanggung jawab hukum bersumber atau lahir atas penggunaan fasilitas 
JURNAL SEHAT MASADA VOLUME XIV NOMOR 1 Januari 2020 ISSN : 1979-2344

dalam penerapan kemampuan ${ }^{1}$ tiap orang untuk menggunakan hak atau/dan melaksanakan kewajibannya. Lebih lanjut ditegaskan, setiap pelaksanaan kewajiban dan setiap penggunaan hak baik yang dilakukan secara tidak memadai maupun yang dilakukan secara memadai pada dasarnya tetap harus disertai dengan pertanggung jawaban, demikian pula dengan pelaksanaan kekuasaan. ${ }^{5}$

Sedangkan tindakan yang harus dilaksanakan oleh Refraksionis Optisien Optometris dalam melaksanakan pekerjaannya diatur melalui Permenkes RI Nomor 19 Tahun 2013 tentang penyelenggaraan pekerjaan Refraksionis Optisien dan optometris. Sebagaimana yang tersirat dalam Pasal 23, dalam melaksanakan pekerjaannya Refraksionis Optisien mempunyai kewajiban untuk : (a) menghormati hak pasien/klien, (b) Merujuk kasus yang tidak dapat ditangani, (c) Menyimpan rahasia pasien/klien sesuai dengan ketentuan peraturan perundang-undangan, (d) Memberikan informasi tentang masalah kesehatan pasien/klien dan pelayanan yang dibutuhkan, (e) Meminta persetujuan tindakan yang akan dilakukan, (f) Membantu program pemerintah dalam rangka meningkatkan derajat kesehatan masyarakat, (g) Mematuhi standar profesi, standar pelayanan, dan standar prosedur operasional Refraksionis Optisien. Sesuai dengan kapasitasnya sebagai produk hukum, Permenkes RI Nomor 19 Tahun 2013 pasal 23 tentang penyelenggaraan pekerjaan Refraksionis Optisien dan optometris memiliki sifat memaksa. Artinya, setiap Refraksionis Optisien yang melakukan kegiatan profesinya di wilayah Negara Republik Indonesia, harus tunduk dan taat pada aturan yang telah ditetapkan.

Meskipun regulasi tersebut telah digulirkan, namun berbagai kasus kesalahan pemeriksaan mata akibat kelalaian dalam pemeriksaan mata. Sebagaimana yang diberitakan oleh Majalah Gatra no. 5 tahun IX, 21 Desember 2003, seorang pasien mengeluhkan penggunaan ukuran kacamata yang tidak sesuai dengan ukuran yang dibutuhkan pasien tersebut di Optik ternama di jakarta, sehingga pasien mengalami rasa mual dan pusing, dikarenakan Refraksionis Optisien di optik tersebut belum memiliki STR, kemudian pasien periksa kembali di Eye Center di Jakarta dengan dokter spesialis mata disana menunjukkan ukuran yang sangat berbeda. Hal itu disebabkan karena para pemeriksa mata di optik ternama tersebut tidak sesuai dengan standar profesi pemeriksaan mata. ${ }^{6}$

Berdasarkan latar belakang yang telah diketengahkan, peneliti tertarik untuk melakukan penelitian dengan judul : "Perlindungan Hukum Konsumen Optikal oleh

Refraksionis Optisien Dalam Upaya
Peningkatan Pelayanan Kesehatan Mata Masyarakat". 


\section{METODE}

Metode pendekatan yang digunakan dalam penelitian ini adalah pendekatan yuridis normatif empiris. Pendekatan yuridis normatif dilakukan untuk mendapatkan data sekunder, dengan menelaah bahan hukum primer (peraturan perundang-undangan), bahan hukum sekunder (karya ilmiah, hasil penelitian, dan literatur), dan bahan hukum tersier (kamus, bibiliografi, ensiklopedia dan indeks), dan didukung dengan data primer, yaitu data yang diperoleh melalui wawancara dengan subyek hukum di lapangan. Dari data primer diharapkan dapat memperoleh fakta mengenai implementasi hukum normatif secara in action pada setiap peristiwa hukum tertentu yang terjadi dalam masyarakat. ${ }^{7}$

\section{HASIL DAN PEMBAHASAN}

Sebagaimana yang termuat dalam Peraturan Presiden Nomor 01 Tahun 2007 tentang pemerintah wajib menyebar luaskan peraturan perundang - undangan yang telah diundangkan dalam Lembaran

Negara Republik Indonesia atau berita negara Republik Indonesia. Teori fiksi hukum beranggapan bahwa begitu suatu norma hukum diberlakukan, maka pada saat itu pula setiap orang dianggap tahu hukum. Ketidak tahuan seseorang akan hukum tidak dapat membebaskan orang itu dari tuntutan hukum. ${ }^{2}$ Namun demikian hasil studi di kota semarang menunjukan, bahwa masih banyak Refraksionis Optisien maupun pasien kesehatan yang dilayaninya tidak memahami hukum, khususnya yang tertuang dalam Permenkes nomor 41 tahun 2015 tentang Standar Pelayanan Refraksi Optisi.

\section{Tabel 1}

\section{Pengetahuan Refraksionis Optisien tentang Isi Permenkes nomor 41 tahun 2015 tentang Standar Pelayanan Refraksi Optisi.}

\begin{tabular}{lcl}
\hline \multicolumn{1}{c}{ Pengetahuan } & Tahu & $\begin{array}{l}\text { Tidak } \\
\text { Tahu }\end{array}$ \\
\hline $\begin{array}{l}\text { Tentang Isi Permenkes } \\
\text { nomor 41 tahun 2015 } \\
\text { tentang Standar Pelayanan }\end{array}$ & 0 & $8(100 \%)$ \\
Refraksi Optisi & &
\end{tabular}

\begin{tabular}{lcc}
\hline Tentang makna Permenkes & 0 & $8(100 \%)$ \\
nomor 41 tahun 2015 & $(0 \%)$ & \\
tentang Standar Pelayanan & & \\
Refraksi Optisi & &
\end{tabular}

Sumber : Wawancara di kota Semarang, diolah tahun 2018

Berdasarkan Tabel 1 dapat diketahui, bahwa dari delapan informan yang di wawancarai, tidak satupun yang mengetahui tentang isi Permenkes nomor 41 tahun 2015 tentang Standar Pelayanan Refraksi Optisi.

\section{Hasil Wawancara :}

Setelah dijelaskan tentang isi dan makna Permenkes nomor 41 tahun 2015 tentang Standar Pelayanan Refraksi Optisi., pada umumnya semua informan menyatakan bahwa, tanpa harus mengenal isi dan makna pasalpasal yang telah disebutkan, mereka selalu memberikan ganti rugi kepada pasien kesehatan yang dirugikannya.

a. Seorang informan mengungkapkan datang kembali ke optikal karena kacamata yang dibeli beberapa hari sebelumnya dipakai 
kurang nyaman dan kurang jelas. Setelah dilakukan pemeriksaan ulang, ternyata ditemukan adanya kesalahan dalam menetapkan ukuran lensa sebelumnya. Meskipun yang membuat kesalahahan itu Refraksionis Optisien, tetapi penyelenggara optikal yang bersangkutan tetap memberikan ganti rugi. Bentuk ganti rugi yang diberikan berupa penggantian lensa dengan ukuran yang baru tanpa dipungut biaya lagi.

b. Dua orang informan mengungkapkan hal yang senada, bahwa ada datang kembali ke optikal karena kacamata yang dibeli beberapa hari sebelumnya kalau dipakai mudah pusing dan tidak nyaman. Ketika akan diperiksa ulang, pasien tersebut menolak, alasannya karena tidak percaya lagi dengan hasil pemeriksaan refraksi yang dilakukan dioptikalnya. Berkaitan dengan hal tersebut, Refraksionis optisien memberi kesempatan kepada pasiennya untuk mendapatkan second opinion dari dokter ahli mata. Bila ternyata ukuran lensa yang tertera pada resep dokter berbeda dengan hasil pemeriksaan refraksi dioptikal, maka lensanya akan diganti sesuai dengan resep dokter tanpa harus membayar biaya lagi.

c. Seorang informan mengungkapkan, bahwa datang kembali ke optikal karena lensa kontak yang dibeli beberapa hari sebelumnya dipakai mudah lepas. Setelah dilakukan pemeriksaan ulang, ternyata ditemukan adanya kesalahan dalam menetapkan diameter dan lengkung dasar (base curve) lensa kontak. Meskipun yang membuat kesalahahan itu karyawannya, tetapi penyelenggara optikal yang bersangkutan tetap memberikan ganti rugi. Bentuk ganti rugi yang diberikan berupa penggantian lensa kontak baru sesuai dengan ukuran yang seharusnya tanpa dipungut biaya lagi.

d. Empat orang informan mengungkapkan hal yang senada, mereka belum pernah mendapatkan ganti rugi dari optikal terhadap pelayanan kesehatan yang didapatnya. Belum pernah bukan berarti tidak mau memberikan ganti rugi, tetapi belum pernah ada pasien kesehatan yang dilayaninya itu minta ganti rugi. Bila nantinya ada pasien kesehatan yang mereka layani ada yang meminta ganti rugi karena kesalahan Refraksionis Optisien, mereka juga akan memberikan ganti rugi. Selanjutnya mereka berargumen dalam perspektif ekonomi, bahwa jika nantinya mereka memberikan ganti rugi itu bukan karena amanat peraturan perundangundangan, tetapi sebagai bentuk pelayanan purna jual untuk menjaga kepercayaan pasar.

Dari hasil studi di kota Semarang dapat disimpulkan, bahwa meskipun para Refraksionis Optisien pada umumnya tidak mengenal isi Permenkes nomor 41 tahun 2015 tentang Standar Pelayanan Refraksi Optisi., namun mereka memiliki tanggung jawab hukum ditinjau dari aspek hukum perdata, karena mereka mau memberikan ganti rugi 
JURNAL SEHAT MASADA VOLUME XIV NOMOR 1 Januari 2020 ISSN : 1979-2344

terhadap kesalahan karyawan yang berada dibawah tanggung jawabnya.

Tabel 2

Alasan Ketidakpuasan Pasien

\begin{tabular}{lc}
\hline $\begin{array}{l}\text { Refraksionis Optisien melaksanakan } \\
\text { apa yang dijanjikan, tetapi tidak } \\
\text { seperti yang dijanjikan }\end{array}$ & $4(50 \%)$ \\
\hline $\begin{array}{l}\text { Refraksionis Optisien melaksanakan } \\
\text { apa yang dijanjikan, tetapi terlambat }\end{array}$ & $4(50 \%)$ \\
\hline $\begin{array}{l}\text { Melakukan sesuatu yang menurut } \\
\text { perjanjian tidak boleh dilakukan. }\end{array}$ & $0(0 \%)$ \\
\hline $\begin{array}{l}\text { Refraksionis Optisien tidak } \\
\text { melaksanakan apa yang dijanjikan }\end{array}$ & $0(0 \%)$ \\
\hline
\end{tabular}

Smuber : Wawancara di Kota Semarang, diolah tahun 2018.

Berdasarkan Tabel 2 dapat diketahui, bahwa alasan ketidakpuasan pasien pada umumnya karena :

Refraksionis Optisien melaksanakan apa yang dijanjikan, tetapi tidak seperti yang dijanjikan.

Hasil wawancara :

a. Seorang informan mengungkapkan, bahwa kacamata yang dipesan dari salah satu optikal, ukuran lensanya tidak sesuai dengan ukuran lensa yang telah diperiksa. Hal itu baru diketahui, ketika informan yang bersangkut melakukan konsultasi dengan dokter yang memberikan resep kacamata. Dokter menyatakan bahwa ketidak nyamanan dalam pemakaian kacamata yang baru saja dibelinya itu, karena ukuran lensanya tidak sesesuai dengan nota pesanan.

b. Seorang informan menggungkapkan, bahwa kacamata yang dibelinya itu lensanya mudah gores, pada hal janjinya kalau lensa plastik sudah diberikan lapisan anti gores lensanya akan tahan gores. c. Dua orang Informan mengungkapkan, bahwa lensa kontak yang dibeli dari optikal kalau dipakai tidak nyaman dan matanya mudah berair. Pada hal ukuran dan jenis lensa kontak yang dibelinya itu berdasarkan hasil pemeriksaan di optikal. Janjinya, kalau lensa kontaknya tidak nyaman akan diganti, tetapi kenyaannya, setiap kali datang ke optikal untuk menyampaikan keluhannya, selalu dikatakan belum adaptasi. Meskipun kedua informan tersebut membeli lensa kontak pada opikal yang berbeda, namun memiliki alasan ketidak puasan yang sama Refraksionis Optisien tidak melaksanakan apa yang dijanjikan.

Hasil wawancara :

a. Seorang informan menggungkapkan, bahwa dia memesan kacamata pada sebuah optikal yang memasang spanduk dengan tulisan "Pesan Kacamata 1 Jam Jadi". Namun pada kenyataannya, saat diambil hasilnya tidak nyaman dipakai karena pemeriksaannya yang terburu buru.

b. Tiga orang informan mengungkapkan, bahwa ketika membeli kacamata pada sebuah optikal, Refraksionis Optisien menyatakan pemeriksaan mata dilakukan secara standar pelayanan. Setelah ada diselidiki. Pada saat pemeriksaan refraksi banyak standar pelayanan refraksi belum dijalankan secara sempurna. Meskipun ketiga informan tersebut membeli kacamata pada optikal yang berbeda, tetapi mereka memiliki persoalan yang sama. 
JURNAL SEHAT MASADA VOLUME XIV NOMOR 1 Januari $2020 \quad$ ISSN : 1979-2344

Dengan demikian dapat dimpulkan, bahwa pada umumnya faktor-faktor yang menjadi alasan ketidak puasan pasien adalah :

Pertama, Refraksionis Optisien tidak melaksanakan apa yang dijanjikan. Kedua, Refraksionis Optisien melaksanakan apa yang dijanjikan, tetapi tidak sesuai dengan yang dijanjikan. Dalam terminologi hukum, kondisi itu dikenal sebagai wanprestasi.

Berdasarkan hasil wawancara dengan 8 Refraksionis Optisien didapatkan suatu temuan, bahwa 2 diantaranya tidak ingat standar pelayanan refraksi. Alasan klasik yang dikemukaan adalah sudah terlalu lama lulus kuliah, jadi tidak ingat standar pelayanan refraksi.

Meskipun masik banyak Refraksionis Optisien yang tidak mematuhi standar pelayanan refraksi, namun demikian Kepala Dinas Kesehatan Kota Semarang tidak akan dapat menjatuhkan sanksi hukum sebagaimana yang tertuang dalam Permenkes RI Nomor 41 Tahun 2015 Tentang Standar Pelayanan Refraksionis Optisien / Optometri. Hal itu disebabkan karena kurangnya pembinaan dan pengawasan dari Dinas Kesehatan.

Dari hasil studi dikota Semarang ini dapat dapat disimpulkan, bahwa perbuatan melawan hukum yang dilakukan oleh Refraksionis Optisien karena tidak melakukan standar pelayanan refraksi dikarenakan kurangnya pengawasan dan pembinaan.

\section{KESIMPULAN DAN SARAN}

Berdasar penelitian yang dilakukan, Kendala dan solusi perlindungan hukum pasien terhadap Refraksionis Optisien dalam pelayanan kesehatan mata, pada umumnya bermuara dari tindakan wanprestasi yang dilakukan oleh Refraksionis Optisien. Hal itu dapat terjadi karena Refraksioinis Optisien tidak melaksanakan apa yang dijanjikan, melaksanakan apa yang dijanjikan, namun tidak tepat seperti apa yang dijanjikan, melakukan sesuatu yang menurut perjanjian tidak boleh dilakukan. Akibat hukum bagi Refraksionis Optisien yang tidak melindungi pasien optikal tidak pernah dilaksanakan karena kurangnya pengawasan dan pembinaan dari dinas kesehatan. Ketentuan tersebut termuat dalam Permenkes RI Nomor 41 Tahun 2015 Tentang Standar Pelayanan Refraksionis Optisien / Optometri.

Berdasar penelitian yang dilakukan, peneliti mengajukan saran dalam rangka melaksanakan fungsi pengawasan dan pembinaan, sebaiknya pemerintah daerah c.q Dinas Kesehatan Kota Semarang mengikut sertakan peran serta organesasi profesi maupun asosiasi terkait, agar Refraksionis Optisien dapat segera memenuhi kewajibannya dalam melaksanakan standar pelayanan. 


\section{DAFTAR PUSTAKA}

Siti Fadilah Supari, 2005, Rencana Strategi Nasional Penanggulangan Gangguan Penglihatan Dan Kebutaan, Depkes RI, Jakarta.

Soekidjo Notoatmodjo, 2010, Etika dan Hukum Kesehatan, Penerbit Rineka Cipta, Jakarta.

Sofwan Dahlan, 2001, Hukum Kesehatan, Badan Penerbit Universitas Diponegoro, Semarang

Purbacaraka, 2010, Perihal Kaedah Hukum, Penerbit Citra Adiya, Bandung,

Majalah Gatra no. 5 tahun IX, 21 Desember 2003

Abdulkadir Muhammad, "Hukum dan Penelitian Hukum”, Citra Aditya Bakti, Bandung, 2004

Jimly Asshidiqqie, Peran Advokat dalam Penegakan Hukum, Orasi Hukum pada acaraPelantikan DPP IPHI Masa Bakti 2007-2012, (Bandung : Konpres, 2008), 